\title{
Espacio privado y espacio público en su deriva tecnológica: Notas sobre la construcción histórica de la subjetividad
}

\author{
Recibido: 06/02/09 \\ Aprobado: 10/02/09
}

Javier Protzel (Universidad de Lima)

RESUMEN: Vista desde una perspectiva de largo plazo, la subjetividad tiene una constructividad histórica. Según los regímenes de conocimiento y visibilidad vigentes en distintas épocas, la vida interior se ha ido progresivamente abriendo paso. El tema de la intimidad es indesligable de la secularización, pues la liberación del yo interior ha sido inversamente proporcional al declive de las grandes figuras de las grandes metanarrativas. De dioses a héroes, de personajes de la novela realista al cine, de ahí al actual antihéroe para llegar a ser uno mismo el narrador narcisista de su propia existencia. Esto también se vincula con la irregular evolución de la relación entre espacio público y espacio privado.

Palabras clave: espacio público - espacio privado - intimidad - narrativas - lectura

Private and public spheres casted adrift by technology. Remarks on the historical building of subjectivity

SUMMARY: From a long-term outlook, the shaping of subjectivity is a historically meaningful matter. It has been unfolded throughout different periods according to different patterns of knowledge and sensitive perception. Intimacy is closely intertwined with secularization, as the releasing of the inner self has been inversely proportional to the fall of the ruling characters of the greater metanarratives. From gods to heros, from realistic novel characters to film fiction, and from there to the contemporary anti-hero, becoming finally oneself the narrator of one's own life.

Key words: Public sphere - private sphere - intimacy - subjectivity - narrative lecture 
"Poesía, se está callada, Escuchando su propia voz".

Martín AdÁN

\section{Introducción}

Y a terminado el primer lustro del siglo, Paul Virilio ${ }^{1}$ hizo una teorización contemporánea de la idea de catástrofe, al constatar la disparidad establecida entre avances científicos y tecnológicos, y hábitat humano, lo cual constituía un verdadero "accidente original". Él vio cómo al haber irrumpido bruscamente en el siglo XIX una era de la velocidad, las productividades agrícola e industrial aumentaron dramáticamente, propiciando la aparición de ciudades inmensas e iluminadas, creciendo las poblaciones con esperanzas de vida extendidas, mientras las distancias se acortaban (la parte afortunada de la humanidad pasó en apenas unas cinco generaciones de la carreta a tracción animal al Boeing intercontinental). Pero estos beneficios evidentes del progreso trajeron consigo pesadas consecuencias, "accidentes" inadvertidos primero, alarmantes después, al devenir en sistemáticos. Para mencionar algunos, el cambio climático causado por las partículas de anhídrido carbónico que hace doscientos años contaminan la atmósfera y las grandes oleadas migratorias pasando de un hemisferio al otro, corolario de la desigualdad (hacia el 2035 habrá unos mil millones desplazados en busca de empleo). Añadamos el gigantesco (¿desproporcionado?) potencial de exterminio de las guerras actuales, la proliferación y privatización de la posesión de armas para responder, además de la escasez de agua a corto plazo y de la anunciada falta de alimentos. Y no menos, la crisis financiera de 2008, catástrofe económica global indisociable del desfase entre el consumismo desenfrenado y exhibicionista de la superpotencia mundial y su insolvencia bancaria, conducente al desmoronamiento planetario de la confianza bursátil, en el marco de unas transacciones e informaciones financieras en línea que por su instantaneidad provocan ese efecto de castillo de naipes. Intelectual del capitalismo tardío, no es casual que desde los años setenta Virilio, urbanista, haya ido deconstruyendo la modernidad prestándole más atención a las consecuencias de la técnica sobre la civilización que al sujeto social como tal.

Más motivado que influido por este autor, me interesa llamar la atención en este ensayo acerca de dos asuntos mutuamente interrelacionados. Por un lado, cómo las transformaciones de la subjetividad se han relacionado en los últimos cuatro siglos con las cambiantes figuras de

1 VIRILIO, Paul. L'accident originel, 2005. 
cada orden simbólico prevaleciente, y por otro, subrayar las configuraciones de la esfera privada con respecto a la pública a lo largo de la modernidad. Ambos hechos convergen por estar inscriptos en determinados regímenes de visibilidad $y$ de comunicación sobrevenidos también a la manera de una larga sucesión de "accidentes" que, yendo muy atrás en el tiempo parecerían, observados desde el presente, formar una ordenada concatenación causal, pero cuya proyección al futuro los presenta -al contrario- como frutos de un azar a veces funesto. El yo privado vinculado al mundo exterior en tanto sujeto autoconsciente es un producto histórico mutante cuyas diversas modalidades no percibimos por la obviedad del presente. Propongo muy sucintamente un modelo de cuatro "momentos", que solo formalmente son sucesivos, dada la heterogeneidad cultural y de las temporalidades sociales:

- la ausencia de una esfera privada propiamente dicha;

- el establecimiento del espacio público moderno claramente separado del espacio privado;
- la profundización del yo interior y el ingreso del espacio público a la esfera privada;

- la extraversión del yo interior a la esfera pública y la crisis del vínculo social.

\section{Secularización y escritura}

Ubiquemos ese grado cero de lo que hoy consideramos esfera privada. La vida diaria habría transcurrido de modo genéricamente colectivo, incluyendo los lugares de dormir y de aseo. Quedándonos en la Lima del siglo XVII, la observancia religiosa de una mayoría analfabeta estaba altamente ritualizada y sometida severamente a la autoridad eclesiástica. La abundancia de procesiones y otras celebraciones impuestas por el derecho divino de un lejano e invisible monarca dejaba pocos resquicios para el cultivo del yo. La plebe más o menos catequizada salmodiaba las oraciones recitadas por los sacerdotes, leídas o aprendidas de memoria, y en la quietud de la vida conventual frailes y monjas escuchaban atentos las Sagradas Escrituras leídas por el prior. $^{2}$ Es interesante esa relación

2 Parte considerable de la superficie de esa Lima pequeñísima la cubrían los numerosos conventos e iglesias. En la tercera década del siglo XVII, con escasamente unos 25.000 habitantes, ya había 43 iglesias y más de 200 oratorios y capillas particulares (LOHMANN VILLENA, G. y J. GÜNTHER DOERING. Lima, 1992, pp. 95-100). Fervor que habría de aumentar con los terremotos de 1687 y 1746. 
entre la obligación de escuchar, la posibilidad de leer y el privilegio de escribir en esas épocas de catolicismo flagelante. Pero entre los miembros de las élites incorporadas a la vida religiosa gradualmente se generalizó la lectura silenciosa, sin movimiento de labios, ${ }^{3}$ y como en ultramar, era signo de la formación de una vida interior independiente de la ascesis mística que buscaba la fusión con lo divino. Contrariamente a la entrega a Cristo de un San Juan de la Cruz o de una Sor Juana Inés de la Cruz, con el "pienso, luego existo" de su obra, René Descartes no solo reconocía la racionalidad del yo individual, sino también los lazos entre lectura y meditación, entre lectura y escritura. Como bien plantea Paula Sibilia, ${ }^{4}$ esos recorridos de la secularización eran inevitablemente zigzagueantes en sociedades de acceso muy desigual a la modernidad, en donde para muchos "la palabra pronunciada conservaba un aura sagrada" mientras otros encontraban en los textos un lugar de escrutinio crítico de la realidad y un punto de apoyo para la toma de distancias. No cabe duda entonces acerca del rol de la imprenta en Europa occidental durante el siglo XVIII para activar el pensamiento libre y la fabulación, en particular frente a la autoridad de derecho divino. Al constituirse los salones y cafés literarios en ámbitos de discusión y conversación franca $-\mathrm{y}$ los teatros en lugares de entretenimiento mundano- los fundamentos religiosos de la narrativa dominante iban siendo racionalmente refutados, instaurándose la cosa públi$c a$, es decir aquello que concernía el interés y/o el deseo de todos, y que todos juntos podían si no resolver, cuando menos abordar.

Con esa secularización del poder, indisociable de la escritura y de la razón argumentativa, llegamos a un segundo momento, caracterizado por la tajante distinción entre espacio público y espacio privado. Richard Sennett, ${ }^{5}$ quien ha estudiado profusamente el tema centrándose en la Francia y la Inglaterra del siglo XVIII, nos recuerda que no somos lo suficientemente conscientes de que junto con el advenimiento del liberalismo vinieron el industrialismo y el funcionamiento de los mercados, modificando en esos países los regímenes de trabajo y dividiendo los ámbitos de la vida diaria entre un afuera y un adentro. Para el ideario ilustrado florecido con la Revolución Francesa, el espacio público es el campo de ejercicio de los derechos ciudadanos, comunes al progreso de todos estos, alcanzable

3 CHARTIER, Roger. El juego de las reglas. Lecturas, 2000.

4 SIBILIA, Paula. La intimidad como espectáculo, 2008, pp. 110-124.

5 SENNETT, Richard. The fall of public man, 1976. 
mediante la voluntad y la razón. Si en lo público transcurre y se edifica la cultura moderna, en el espacio privado, a la inversa, permanece "la naturaleza", entendiéndosele como aquello ajeno al artificio, atado inexorablemente a la biología y a la afectividad: la familia, el cuerpo, los sentimientos personales, la enfermedad. ${ }^{6}$ La densificación de la interacción en un medio urbano ampliado también explica esa separación de lo público frente a lo privado, ${ }^{7}$ pues en esa sociabilidad modernizante imperaron, junto con las nuevas ideas, las apariencias de cada cual, a veces con profusa ostentación, llegando a ser tan estrictamente codificadas y mantenidas por "leyes suntuarias" hace dos siglos y pico que resultarían inconcebibles a inicios del siglo XXI. ${ }^{8}$ Predominó el lucimiento público de una clase social emergente, la burguesía, poseedora de bienes, fortuna y conocimientos, pero no de poder político ni linaje. Las burguesías eran apenas minorías selectas cuya visión del mundo sin embargo encabezaba la secularización, desacralizando al Estado monárquico y defendiendo los fueros de la vida privada.

Será a lo largo del siglo XIX, a medida que los países occidentales se industrializan, cuando esa separación burguesa de lo público y lo privado se expande, capilarizándose en las clases

6 Ibídem, pp. 89-106.

7 Quizá un rasgo del Japón moderno y secularizado sirva de ejemplo de esa separación entre lo público y lo privado. Hasta los años noventa y aun más adelante, llamaba la atención la homogeneidad vestimentaria y de aliño personal de los japoneses en el espacio público, en particular de empleados de oficina, funcionarios y ejecutivos, casi la totalidad de ellos vestidos con trajes grises, camisa blanca y corbata, como si ese "uniforme" de la modernidad occidental fuese la tenida adecuada para presentarse en el tráfago público de las grandes oficinas y estaciones de tren trabajando siempre apurados. Lo cual contrasta con el uso familiar del kimono en el hogar, en un medio doméstico más apegado a la tradición y a la parsimonia.

8 Señala Sennett que en el Londres o el París de mediados del XVIII los diferentes niveles sociales e incluso los oficios de cada cual podían ser identificados en la calle. Quizá la experiencia de la contigüidad con desconocidos, el "roce", fuese una novedad. Esto llegaba al extremo de que para las clases más altas, al cuerpo se le tratase como a un maniquí, a un artificio "disfrazado" para presentarlo en público. Manchas de pigmento rojo podían cubrir la mejilla de una mujer o de un hombre, o bien el rostro íntegro podía estar embadurnado de blanco. Las inmensas pelucas, a la orden del día, se usaban para significar distinción. Las cabelleras femeninas llegaban a ser decoradas con maquetas de navíos, canastas con frutas y eventualmente escenas históricas en miniatura. Abogados, contadores y comerciantes lucían togas y cintas distintivas en un medio en el cual el arreglo personal se parangonaba con la manera de hablar y el léxico empleado, otra manera de identificarse frente a los otros (op. cit., pp. 65-76). 
medias nacientes, llamadas también pequeña burguesía, y en parte de la clase obrera. La cuestión del número importa por asociarse con la popularización de la lectura. En particular crece la fabulación novelesca, y junto con ello la balanza va inclinándose hacia la esfera privada, es decir hacia una exploración de la intimidad a través de los relatos de ficción, expendidos ya en grandes cantidades en el mercado, con lo cual sobreviene una transformación de la subjetividad que marca un tercer y largo momento. Pero subrayemos antes que mientras en el primer momento la esfera privada prácticamente no existía y el ojo de Dios estaba firmemente asociado al poder terrenal -del Rey, de la Iglesiael sujeto no "veía" las figuras del poder, a menos que fuese a venerarlas genuflexo en una iglesia. Sin distancia entre sujeto y objeto, lo cultual predominaba en la contemplación respecto a lo que llamaríamos ahora estético. No extrañe entonces que los ejemplos obligatorios provengan de la pintura religiosa -desde cualquier Madonna col Bambino del quattrocento italiano hasta Zurbarán o Ribera en el barroco español- ni que en las artes escénicas de ese país el auto sacramental haya sobrevivido al esplendor humanista de su Siglo de Oro. Es cierto, no fueron únicamente figuras religiosas, pues la plástica del Renacimiento abundó en imágenes inspiradas en la antigüedad clásica, con alegorías mitológicas, o mezcladas con motivos cristianos, como en Miguel Ángel. En cambio, debe destacarse que posteriormente ya no se tratará de figuras religiosas o mitológicas, sino de personas reales, reconocidas públicamente ya sea por su heroísmo defendiendo una causa colectiva, ya sea por sus cualidades en relatos de ficción. Washington, Robespierre o Bolívar son personajes históricos y venerados pero inscritos en mitologías laicas acordes con la mentalidad de sus épocas. A diferencia del respaldo eclesial $\mathrm{y}$ del temor al castigo infundido por las figuras religiosas, estas otras requirieron de una dinámica política militante para dejar huella en la memoria colectiva, así como de facilidades técnicas e institucionales para perennizarse: de lectores que se identificasen con sus luchas y supiesen de ellos a través del panfleto o del diario, y de intelectuales de nuevo cuño que los acompañasen y elaborasen sus hagiografías. Resaltemos la exterioridad de sus perfiles; son efectivamente "hombres públicos", cuyas vidas interiores cuentan poco, o en todo caso son funcionales a sus liderazgos, quedando sus defectos relegados al anecdotario, siendo recordados más por sus cualidades irreprochables. Pétreos e inmóviles como las estatuas con que se les rememora, suelen ser las figuras fundacionales del Estado-nación moderno, protagonistas de los relatos grandiosos estudiados en los manuales escolares. Esas epopeyas de la historia oficial no tendrían efectivamente 
mayor significación sin el marco institucional que rige la vida social desde fines del siglo XIX: la educación escolar obligatoria con la cual desde la infancia se aprende los símbolos nacionales y cuáles son sus prohombres, la temporalidad cívica jalonada por efemérides que celebran a héroes y a sucesos notables, la información periodística, y hasta el trazo mismo de las urbes, marcado por grandes ejes viales que llevan nombres célebres y espacios de encuentro marcados por monumentos de homenaje.

\section{La narrativa en el espacio público}

Contrapartida de esa consolidación de lo público en la civitas moderna es la metamorfosis casi paralela de la subjetividad, al crecer la búsqueda de sí mismo no en lo público sino en la intimidad, desatando "una intensa modernización de la percepción" que cambia el punto de vista desde el cual se valora la existencia. ${ }^{9}$ Esto ocurre a lo largo del siglo XIX y se prolonga hasta fines del XX, junto con la expansión de la lectura. Hacía mucho que el lector medio había dejado de leer para conocer a Dios o para aprender, pues desde el siglo XVIII con las novelas se aprendía roles sociales y, gracias a la identificación con los personajes e inmerso en las tramas, el lector descubría y realizaba imaginariamente sus deseos: era él y otro al mismo tiempo. La profundidad de esta introspección traduce el afán de buscar la verdad de los sentimientos propios en el espejo de la ficción literaria, y sobre todo de decir lo que se es, contando las propias historias en cartas a confidentes secretos y en diarios personales. A mediados del siglo XIX, aumentó furiosamente la práctica de la escritura entre las clases medias europeas, gracias a ese propósito de cultivarse y autoafirmarse, ${ }^{10}$ animado según Foucault por el deseo de contar la propia sexualidad. ${ }^{11}$ No obstante esta última observación, es en este marco que aflora el amor romántico. Anthony Giddens nos recuerda que la palabra 'romance' (en alemán, italiano y francés) designa al mismo tiempo una historia contada y la vivencia de un amor sublime, ajeno a la sensualidad del amor-pasión, todo lo cual corresponde a la emergencia de la novela (roman en alemán y francés) como forma narrativa. Pero este senti-

9 SIBILIA, Paula. Op. cit., p. 116.

10 Ibídem, p. 76.

11 Mientras que hasta el siglo XVIII la confesión del pecado carnal había sido una penosa obligación, al producirse esta nueva subjetividad el deseo de decirse a sí mismo se impone “[...] La obligación de confesarnos está desde entonces [el siglo XIX] tan profundamente incorporada que ni la sentimos como el efecto de un poder que nos constriñe, nos parecre al contrario que la verdad, en lo más secreto de nosotros, no pide más que ver la luz..." (FOUCAULT, M. Historie de la sexualité 1. La volonté de savoir, 1976, p. 80). 
miento romántico está inevitablemente asociado con la libertad de cada una y uno, al percibir (y proyectar en el texto literario) al amor-fusión como el medio anhelado, conquistado y conscientemente elegido para la autorrealización personal. ${ }^{12}$ Esto implicó, por un lado, la estetización del sufrimiento y la tematización de la melancolía, pues el atractivo de la literatura romántica era (¿es?) el sentir reflejada la experiencia amorosa propia en el personaje del texto, en particular las desventuras que motivaban la afición misma a la lectura. De ahí que la popularidad del tema de los amores imposibles por tabúes de clase $u$ otros, del afecto no correspondido, o de los conflictos por la identidad fuesen, mucho más allá de una simple simpatía, a una entrega de la vida. ${ }^{13}$

Pese a vaivenes y simultaneidades, puede constatarse cierto recorrido digamos descendente de las antiguas figuras de veneración religiosa a las heroicas nacionales a medida que el yo narrativo se afianzó. La centralidad que este último alcanza durante el romanticismo toca, valga la salvedad, solo a las capas superiores y medias, y en América Latina habría que añadir occidentalizadas, al ser muy minoritarias. Esta expansión no obstante fue en aumento y se extendió conforme avanzó el siglo XX. Junto con la literatura, y eventualmente antes que ella, el desarrollo de los espectáculos públicos (teatro, ópera, variedades ligeras), de la lectura de novelas de folletín y noticias sensacionales en la prensa popular, de la música escuchada colectivamente pero disfrutada en la soledad interior, así como el advenimiento de las imágenes en serie ha sido un proceso muy estudiado, sobre el cual no insistiré. En cambio, sí debe enfatizarse el aspecto poscolonial de esta evolución. A la escisión entre lo público y lo privado del modelo de Sennett presentado más arriba debe ponérsele matices singulares al pensarlo en América Latina, debiendo referirme aquí al Perú. Además del propósito evangelizador de la colonización española y del establecimiento de poblados que en buena parte eran recintos conventuales por la cantidad de iglesias, la obediencia estricta de las prescripciones religiosas virreinales probablemente sentó en la población un fundamento para la observancia moral, independientemente de que este manipulase el temor al infierno o sentimientos de culpa. Gonzalo Portocarrero plantea que el resquebrajamiento de este orden tras la emancipa-

12 GIDDENS, Anthony. The transformation of intimacy. Sexuality, love, and eroticism in modern societies,1992, pp. 39-40.

13 Es un conocido ejemplo la ola de suicidios provocados a inicios del siglo XIX por la lectura de Las desventuras del joven Werther de Johann Wolfgang Goethe. 
ción no correspondió en realidad a una secularización. El reemplazo de régimen monárquico de Madrid por gobiernos criollos militares o liberales ocurrió sobre un vacío de religiosidad laxa, sin que hubiera un orden cívico republicano realmente interiorizado. El mantenimiento de las jerarquías étnicas y económicas estuvo a la par con la generalización de la transgresión, con " [...] la creación de una complicidad, de una comunidad que la aprueba y goza con ella" en la sociedad criolla. ${ }^{14}$ Esta hipótesis sobre la cultura criolla me parece esencial para esbozar una reflexión sobre los derroteros de las subjetividades en el país. Habrá que señalar la fragilidad de esa separación entre espacio público y pri- vado, en la medida en que la ciudadanía y la discusión argumentativa eran privilegio solo de un selecta minoría. ${ }^{15}$ Si bien esta gozaba formalmente de tal condición, no se trataba de sujetos realmente insertos en una sociedad moderna. Los conflictos del yo frente al mundo adolecían del color de una subalternidad en que se adoptaba lo postizo a falta de poder ser auténtico, con la virtual imposibilidad de ejercer el ideario liberal, pues era un stablishment político estamental y sobre todo racista, que veía en el mestizaje una mancha. Marcel Velásquez ${ }^{16}$ ha calificado de protésicas a las subjetividades del siglo XIX que aparecen en la literatura de la época, y sin duda, en la vida diaria. ${ }^{17}$

14 PORTOCARRERO, Gonzalo. “La transgresión como forma específica de goce del mundo criollo", en LÓPEZ MAGUIÑA, S. et al. Estudios culturales. Discursos, poderes, pulsiones, 2001, p. 544.

$15 \mathrm{Al}$ respecto recordemos que en la elección de Manuel Pardo en 1872 participaron algo menos de 3.800 electores en un país de unos 5 millones de habitantes.

16 VELÁSQUEZ, Marcel. “Novela romántica y nación: Memorias f (r)iccionales y subjetividades protésicas", en HAMANN, M. et al. Batallas por la memoria: Antagonismos de la promesa peruana, 2003.

17 Protésica la identidad de Edgardo, protagonista de la novela del mismo nombre de Luis Benjamín Cisneros, que narra la historia de un modesto joven provinciano y de Adriana, una chica quien tras perder su virginidad por amor (la misma noche de la muerte de su madre), se casa con él. Pero Edgardo es poseído por las lecturas en que se enfrasca. Le infunden un apego confuso a las hazañas de los conquistadores españoles y al heroísmo de las guerras de Independencia, convirtiéndose en "[...] un sujeto que se desubjetiviza de su presente chato y miserable y se inscribe en la subjetividad ajena de los héroes militares [...]" (VELÁSQUEZ, M. Op. cit., p. 304) terminando muerto en una batalla peleando por Echenique, y dejando a Adriana viuda. Protésica la identidad del Marqués de Montenegro, en Salto atrás de José Antonio de Lavalle. En esta novela, la marquesa, su esposa, es violada por un negro en ausencia de su anciano esposo. Veinticinco años más tarde, nace el primogénito del joven marqués de Montenegro. Es un bebé negro, y el padre, sabiéndose mulato, y dolido por esa verdad hasta entonces oculta, lo mata y se recluye en el Convento de la Recoleta (ibídem, pp. 306-310). 
De ahí que los malestares del corazón se atraviesen en esa literatura con los buenos propósitos de fundación de una nación libre y democrática, o que a la inversa, el sufrimiento de las tramas románticas se entremezcle con el racismo. Frente a la realidad poscolonial, ese idealismo lisiado se convierte en muestra de un destiempo histórico. El yo latinoamericano que se entrega intensamente a tramas melodramáticas no es exactamente el mismo que el europeo, y no solo por una cuestión de atraso. La práctica criolla de la transgresión no ha significado la desaparición de la religiosidad; el respeto y la sumisión impuestos por el catolicismo se tradujeron a la vida civil, instaurándose modelos laicos de santidad y obediencias absolutas a los jefes, especialmente en países con alta población de origen indígena. ${ }^{18}$ De esta suerte, la afición popular al melodrama vino mucho menos por la lectura que por el cine (y por supuesto, después la televisión), al mismo tiempo que se mantuvieron vivas la religiosidad popular, ocurriendo una "compenetración devocional con la pantalla"19 y aprendiéndose la ciudadanía y el culto a los héroes en los manuales escolares. Para Hermann Herlinghaus el relato intimista y el social convergen en tanto "el conflicto amoroso es vivido como problema de justicia”, siendo la sensibilidad melodramática latinoamericana un ingrediente de un "rito de iniciación en la modernidad" cuyo centro se encuentra en la subjetividad femenina "[...] que busca una identidad emocional (sexual) en un doble intento de liberación y conformis$\mathrm{mo}^{\prime \prime}{ }^{20} \mathrm{Me}$ parecen factores diferenciadores latinoamericanos con respecto al Occidente tanto ese aprendizaje de la ciudadanía como el acceso mayoritario a la ficción mediática, "tardíos" ambos, porque no corresponden a la periodización que Bernard Miège hace del espacio público en Europa y Estados Unidos, sino a la supervivencia de cierta memoria popular. ${ }^{21}$ Destaco que este autor di-

18 Baste con ver hasta el día de hoy el estudiado fervor ante las cámaras de televisión del presidente y sus ministros en el Te Deum por una efeméride, además de los notables locales en ciudades del interior.

19 MONSIVÁIS, Carlos. Aires de familia. Cultura y sociedad en América Latina, 2000, p. 36.

20 HERLINGHAUS, Hermann. “La imaginación melodramática. Rasgos intermediales y heterogéneos de una categoría precaria", en HERLINGHAUS, H. (ed.). Narraciones anacrónicas de la modernidad: Melodrama e intermedialidad en América Latina, 2002, p. 28.

21 Corolario de esa vigencia de la memoria en el presente es la intermedialidad latinoamericana, valga decir una intertextualidad de las narrativas que a su vez organiza la interrelación entre los medios y les asigna funciones a cada uno. Así, resulta imposible comprender el cine temprano sin la canción (y la radio), ni la importancia de la telenovela sin la 
ferencia en esos países entre el largo periodo de masificación de la prensa desde mediados del siglo XIX -que arrastra consigo novelas de folletín, crónicas rojas y escándalos políticos, todo ello dado por la lectura- y el del acceso a los medios audiovisuales a mediados del siglo XX. Salvo por matices argentinos y uruguayos, la condición ciudadana se consolida en este lado del mundo precisamente junto a la masificación de los medios: la prensa amarilla, la radio y la televisión alrededor de los años sesenta, y no a cerca de un siglo de distancia. El espacio público moderno confluye entonces con el acceso a una cultura del entretenimiento, pasándose a vivir en el seno de la "burbuja comunicacional" del hogar, vale decir a la penetración simultánea del espacio público dentro de la esfera privada, la cual es "intelectualizada" por los discursos informativos. $^{22}$

\section{Tiranías de la intimidad}

La distinción con respecto a la periodización de Miège es crítica. Salvo por sus minorías educadas, nuestros países no se caracterizaron por la activi- dad ciudadana ni los espacios públicos pintados por Richard Sennett. Este sostiene que durante el siglo XX se ha erosionado

[...] el delicado balance entre vida pública y privada $[. .$.$] entre un domi-$ nio impersonal en que los hombres podían investir un tipo de pasión, y un dominio personal en el que podían investir otra. ${ }^{23}$

Se lamenta del " $[\ldots]$ borrado progresivo de la res pública por la creencia de que los significados sociales son generados por sentimientos individuales $[\ldots]]^{\prime \prime},{ }^{24}$ pues estos impiden comprender cabalmente que en el espacio público siempre se despliegan relaciones de poder, lo cual obliga, en aras del mutuo respeto y la experiencia social civilizada, a mantener distancias. Se generaliza lo que él llama las "tiranías de la intimidad", al valorarse la realidad social proyectando en ella solo el parecer o el gusto particular. En su perspectiva, la vida privada ha sido invadida por el espacio público, y la televisión, siendo un dispositivo de la intimidad, forma parte de esto al contribuir al conocimiento de

que previamente tuvo la radionovela, y a su vez el folletín impreso predecesor, a medida que se retrocede en el tiempo y las audiencias se achican (HERLINGHAUS, H. Op. cit., pp. 37-49).

22 MIÈGE, Bernard. "L'espace public: Au-delà de la sphère politique". Hermès 17-18, 1995, pp. 50-57.

23 SENNETT, Richard. Op. cit., p. 338.

24 Ibídem, p. 339. 
cada grupo social pero haciendo también que la interacción social decline a favor de la experiencia personal. Al aparecer, esta "paradoja del aislamiento y la visibilidad" no solo disminuye la posibilidad de proyectar la información en acción política. El vínculo social se retrae, pues el televidente pierde conciencia de que el político moderno es apenas un mediador entre él y otro ciudadano televidente que está viendo lo mismo. Más aún, sostiene Sennett, la búsqueda del vínculo horizontal y amistoso con el televidente característico de la neotelevisión suprime o escamotea el carácter ideológico de los asuntos tratados a favor de los aspectos personales del político en pantalla. ${ }^{25}$ Valga subrayar que esto no ha sido consecuencia del medio televisivo como tal. Esta obsesión por "tener buena imagen" y apreciar a las figuras públicas por su simpatía expresa más bien que el uso social de una tecnología es culturalmente selectivo, tratándose, en este caso, de una aún mayor expansión de la esfera íntima, que por supuesto va mucho más allá del tema político.
Lo importante para quienes leemos a Sennett desde América Latina es constatar la singularidad y la fuerza de esa profundización en nuestro continente, ya que para las grandes mayorías el paso de lo oral y a menudo semirrural a lo urbano y audiovisual ha sido abrupto, mediando solo limitadamente esos rasgos de conciencia cívica y de sensibilidades cultivadas con la lectura a lo largo de varias décadas de experiencia social preelectrónica. El "tipo ideal" presentado por este autor debe ser modificado en nuestras latitudes. La cultura contemporánea del entretenimiento en el Perú ha sido principalmente la televisión comercial. La audiencia televisiva nacional terminó de consolidarse hacia inicios de los noventa, lo que prácticamente significa que esta nació recién con la neotelevisión, mientras la paleo-televisión (cuya partida de nacimiento se remonta a 1958) fue conocida por un público de mucho menor volumen y mayor componente mesocrático. ${ }^{26,27}$ La memoria colectiva cívica y/o literaria se ha raleado progresivamente en nuestro medio, sobre todo si va más allá de

25 Ibídem, pp. 282-285.

26 CASETTI, F. y R. ODIN. “De la paléo- à la néo-télévision". Communications 51, Télévisions/ mutations, 1990; ECO, U. La estrategia de la ilusión, 1986.

27 Un estimado de POP (Peruana de Opinión Púbica) de 1964 señalaba que había unos 65.000 hogares equipados con receptores de televisión, lo que aumentó a 292.000 en 1969, dando apenas 3\% y $12,5 \%$ de hogares equipados para esas fechas. Para 1980 alcanza el $42 \%$, llegando a $72 \%$ en 1994, pese al brutal descenso del poder adquisitivo de 1984 a 1992, y a más de $78 \%$ al voltear el siglo. Son promedios nacionales, que en las principales ciudades superan el 90\%, llegando a más del 98\% en Lima. Definiéndolas genéricamente, la paleotelevisión es el medio naciente, con recursos técnicos limitados y una vocación tutelar, que 
una o dos generaciones. Se contrapone a la de una mayoritaria población de origen inmigrante, andino o no, cuya ciudadanía social ${ }^{28}$ logró luchando por hacerse de un lugar en la urbe, e ingresó a un rápido proceso de modernización en el cual la televisión y la publicidad probablemente hayan desempeñado roles tan o más importantes que los manuales escolares, la lectura y el Estado. De ello se desprenden dos aspectos que subrayo. Primero, la singularidad de dos generaciones cuyo contacto con las imágenes en movimiento (y con las tecnologías interactivas poco después) provino directamente de lo oral, sin tradición previa de la lectura crítica y relato escrito. $^{29} \mathrm{Y}$ segundo, que desde la década de los ochenta, los movimientos políticos y sociales masivos formados según los cánones partidarios modernos declinan después de haber nacido y crecido en varias oleadas desde la década de los treinta hasta la de los ochenta. Es verdad que este cambio fue indisociable de una crisis de las expectativas generadas por sucesivos gobiernos cuyos resultados económicos sembraron el desánimo en una ciudadanía que, sin embargo, había prestado oídos a sus discursos. $\mathrm{Al}$ terminar el primer régimen de Alan García (1985-1990) la inflación acumulada no tenía precedentes y la recesión productiva iba descomponiendo el tejido ocupacional. No era que el empobrecimiento generalizado del país y el terrorismo de por sí causasen una transformación de la subjetividad. Más bien se aceleraba y se hacía más perceptible un proceso de individuación que venía de más atrás, precisamente por la agitada vida de las ciudades y la densificación del contacto dentro de ellas, sin que las nuevas situaciones estuviesen respaldadas por proyectos de vida sólidos. La familia popular mutaba de extensa rápidamente a nuclear en medio de una inflación que sobrepasó los $7.500 \%$ en el periodo mencionado, a lo que se añaden las cifras de la década anterior y del ajuste neoliberal implantado por Fujimori.

lo orienta a "llevar a casa" la educación y la cultura, desde cierta postura paternalista y censora. En cambio, la neotelevisión intenta establecer una relación más horizontal con la audiencia, suprimiendo las barreras de entre un lado y otro de la pantalla mediante la simulación de una relación más personalizada con el televidente.

28 LÓPEZ JIMÉNEZ, Sinesio. Ciudadanos reales e imaginarios. Concepciones, desarrollo y mapas de la ciudadanía en el Perú,1998.

29 Es cierto que gracias al crecimiento de las redes televisivas se da un paso importante para vencer el tradicional aislamiento de las provincias. En 1993 solo el 34,8\% de los hogares equipados con televisión se encuentra en Lima, contra el 47,5\% de 1979. En la capital, los hogares equipados con por lo menos un receptor aumenta de $73.6 \%$ en 1979 a $96 \%$ en 1993. Fuente: CPI, Compañía Peruana de Investigación de Mercados. 
Ante esos escenarios es imposible siquiera imaginar un espacio público de discusión y razonamiento argumentativo como el francés y el inglés descripto y teorizado por Sennett y varios europeos. ${ }^{30}$ En sus "tipos ideales", estos funcionaban por el equilibrio entre la esfera pública y la privada: la impersonalidad de la primera protegía la intimidad de la última. En cambio, a falta de instituciones creíbles y estables que respaldasen un espacio público al cual pudieran incorporarse plenamente los excluidos económica y culturalmente, se instaló la sospecha y se oscureció el panorama de la participación cívica. Naturalmente, el espacio público no puede desaparecer, pero en ese marco definitivamente pierde consistencia y el rumbo social se pulveriza, siendo menos percibido en un gran horizonte colectivo que como una serie de proyectos particulares y de relaciones interpersonales. Lo que ocurrió en el Perú de las dos últimas décadas del siglo pasado fue un caso severo del colapso económico del Estado de bienestar en otras partes del globo. De ahí que la ilusión de "salir adelante" individualmente se haya ido fortaleciendo y la percepción de la propia subjetividad sea la de un relato o una travesía en el tiempo. Empero, pese a la consiguiente disminución de la confianza en los discursos del poder, los sistemas políticos no desaparecen. Por ello sus liderazgos se transfiguran para responder a las simpatías personales que puedan suscitar según características ajenas a sus programas, al mismo tiempo que la opción del votante se inclina a favor de aquellas ofertas que convengan a su propio proyecto individual. Nada más natural, por cierto, pero modelos anteriores de sujeto social como el del militante, así como las figuras de la causa justa y del sacrificio en nombre de valores colectivos se reducen, si no tienden a desaparecer. ${ }^{31}$ Precisamente Sennett afirma el "declive del hombre público", destacando que desde la segunda mitad del siglo XX la gente de mayor fama o reconocimiento lo obtiene por razones que tienen poco o nada que ver con su desempeño cívico, aun tratándose de los políticos. A diferencia de la dimensión sobrehumana que tuvieron las figuras de la santidad y del heroísmo militar, o incluso el endiosamiento de los líderes carismáticos de la política de la primera mitad del siglo, estos personajes se humanizan con la secularización, y la gente establece otro tipo de contrato comunicacional con ellos. La atención prestada a la simpatía perso-

30 FERRY, Jean-Marc. "Las transformaciones de la publicidad política", en VARIOS AUTORES. El nuevo espacio público, 1998.

31 PORTOCARRERO, G. "Las nuevas poéticas del sujeto en la sociedad peruana”, en LOHMANN VILLENA, G. Historia de la cultura peruana, tomo 2, 2001, pp. 561-597. 
nal y a detalles de la vida privada de los políticos nos dice que el ciudadano pasó a funcionar con mecanismos de identificación y proyección semejantes a aquellos desplegados en su relación imaginaria con otras figuras del espectáculo, lo cual obliga a los candidatos a mostrar su privacidad, por supuesto maquillada por expertos en márketing.

'Tiranía de la intimidad' no solo para los notables sino también para la mujer u hombre medios, en la medida en que la valoración en auge de los rasgos personales trasciende la política. Más aún, no se origina en ella sino en un clima de época más general. La desconfianza en el espacio público se desencadena en espiral, pues dicho en breve, la propia conciencia deja de ser fuente de autorreconocimiento moral, deslizándose la autoestima al reconocimiento recibido de los otros. En su fuero más profundo, el sujeto dimite de la visión convivial moderna (o comunicativa, empleando el término habermasiano) de lo social. Si en política se dejó de buscar el progreso y la justicia para perseguir el éxito y el provecho personales, la inte- racción social corriente deviene en algo más competitivo y calculado que amistoso y candoroso. Es también una dimisión del compromiso con los otros subyacente a la socialidad, y de su trasfondo afectivo, a favor de un afecto hacia sí mismo basado en el reflejo que despide el espejo de los otros. Crece rápidamente, por lo tanto, una cultura del narcisismo, marcando el cuarto momento de las transformaciones de la subjetividad anunciadas al inicio del texto. En un trabajo seminal, un conocido crítico estadounidense señalaba que el proceso contemporáneo de inflación narcisista del yo privado, lejos de glorificarlo es la crónica de su desintegración. ${ }^{32}$ No es necesario suscribir la visión amarga de Christopher Lasch ${ }^{33}$ para percibir en el narcisismo un aspecto central de las sociedades de la modernidad tardía, sean estas industrializadas o no, y este excede ampliamente las dimensiones del cuidado personal y de la política. Detrás de las figuras del éxito, como los logros del político o del alto funcionario, del triunfo del deportista o la fortuna del empresario, la belleza de divas y

$32 \mathrm{LASCH}, \mathrm{Christopher.} \mathrm{The} \mathrm{culture} \mathrm{of} \mathrm{carcissism.} \mathrm{American} \mathrm{life} \mathrm{in} \mathrm{an} \mathrm{age} \mathrm{of} \mathrm{diminishing} \mathrm{expecta-}$ tions, 1979, p. 69.

33 Señala que "Nuestra sociedad, lejos de buscar la vida privada a expensas de la vida públi$\mathrm{ca}$, ha hecho que las amistades largas y duraderas, las relaciones amorosas y los matrimonios se vuelvan crecientemente difíciles de lograr exitosamente. A medida que la vida social se vuelve más y más belicosa, y bárbara, las relaciones personales, que ostensiblemente proveen alivio frente a esas condiciones, toman el carácter de un combate [...]" (ibídem). 
divos, hay una afirmación de poder. $\mathrm{O}$ en otras palabras, la visibilidad pública, al convertirse en objetivo de luchas simbólicas, se politiza. Destaquemos que el espacio público no solo ingresó en la vida privada, paralelamente se expandió. Los roles desempeñados por cada miembro de la familia se fueron especificando, generándose vínculos particulares con el mundo exterior. En la familia extensa o nuclear tradicional el pater familias mandaba como en un fortín cerrado; la mantenía con su salario, y además votaba ("representándola" en el espacio público) y hasta cierto punto le transmitía los valores que venían de afuera. Eso en buena parte desapareció, cediendo paso a un grupo de parentesco más diferenciado e igualitario que ya no brinda la misma seguridad y continuidad identitaria. Los tres elementos del antiguo lema conservador Dios, patria, familia se reforzaban mutuamente, vigorizando al orden patriarcal, haciéndolo funcionar mediante disciplina y represión sexual. No llame la atención, entonces, que al abrirse las compuertas del espacio privado la familia haya descubierto nuevos ámbitos de interacción y de producción.

Obviamente, esto se asocia con la expansión de la vida urbana y la multiplicidad de formas de socialización. La prensa escrita, la radio, el cine fueron ensanchando lo público, es cierto, pero la televisión introdujo en el hogar mismo un nuevo tipo de visibilidad, precipitando identificaciones y proyecciones más puntuales, estables e intensas. Lo cual es indesligable del rápido crecimiento de la inversión publicitaria en el mundo, cuya curva de ascenso en términos porcentuales del PBI da cuenta de un fenómeno económico al mismo tiempo que de una dinámica antropológica de extroversión de la esfera privada. Muestra de ello es la profusión de paneles que iluminan nuestras ciudades y la transmisión perenne de spots comerciales televisados, a lo que se han añadido los anuncios en internet y en teléfonos móviles.

La sostenibilidad de las grandes empresas en los países más avanzados ha requerido mantener niveles adecuados de rentabilidad, aún a costa del empleo. Ello ha implicado esfuerzos para acelerar las tasas de rotación del capital y ampliar mercados, o en todo caso mantener las ventas. De ahí que a medida que extensos sectores accedían a bienes y servicios antes inalcanzables, el tratamiento de la demanda pasaba a ocupar un lugar central en la preocupación para mantener andando la maquinaria económica, hecho al que es imposible aludir sin relacionarlo con innovaciones en informática y telecomunicaciones aplicadas a tecnologías de la información como a las de gestión industrial y comercial. La diversificación de la producción en el capitalismo tardío, tanto en el plano de su finalidad y uso, como en el establecimiento de grados variados de calidad y segmen- 
tos desterritorializados de compradores, al igual que la invención y consiguiente estratificación de marcas han sido antídotos decisivos para evitar o postergar la saturación de la demanda. Sin descartar la práctica de la obsolescencia planificada, las armas empresariales impuestas en el espacio público para que no disminuya el consumo han sido la publicidad y el márketing. El deseo de poseer se ajusta perfectamente al afán mercantil de ofrecer, lo cual naturaliza en la percepción común algo que en realidad es artificioso, una práctica simbólica cuyo corolario en el ego del consumidor es la "atribución de poder y potencialidad a las cosas que se va a comprar". 34 A ese respecto es interesante el distingo entre el tipo ideal de una "sociedad de productores" orientada a "la obtención de seguridad" mediante adquisiciones destinadas a "resistir los embates del tiempo, el desgaste y todo signo prematuro de caducidad" frente a una "sociedad de consumidores" en que prima el disfrute inmediato de lo novedoso. ${ }^{35}$

Entre una y otra medió la mutación del capitalismo. El trabajo fabril y la burocracia dejaron su rol de eje de la economía moderna, y frente a la temporalidad continua de la familia ahorrista y cohesionada que formaba a lo largo de décadas un patrimonio intergeneracional surgió un tiempo estallado, con rupturas y discontinuidades, de una sociedad de consumidores mucho más individuada. En ella importan más las pulsiones por poseer y gastar, que en palabras Zygmunt Bauman provocan "[...] un aumento permanente del volumen y la intensidad de los deseos" 36 y afianzan cierto vínculo simbólico con el mundo. Y siendo insaciables, resultan perfectamente funcionales a las economías más avanzadas, necesitadas de una lógica de eliminación de la producción usada $\mathrm{u}$ obsoleta y su constante reemplazo por una más avanzada, más fina o simplemente a tono con la moda. Además de padecer de los avatares de la flexibilidad laboral, el sujeto de la modernidad tardía está condenado a negociar con entornos inciertos y móviles. No solo en el trabajo, sino en sus relaciones interpersonales, quedando atrás esa cómoda separación de lo público y lo privado que había protegido la continuidad e identidad de las generaciones antecesoras. Pero siguiendo el razonamiento de Sennett, ${ }^{37}$ las 'tiranías de la intimidad' se extremaron. El crecimiento exponencial de los artículos y

34 SENNETT, Richard. La cultura del nuevo capitalismo, 2006, p. 123.

35 BAUMAN, Zygmunt. Vida de consumo, 2007.

36 Ibídem, p. 50.

37 SENNETT, Richard. La cultura del nuevo capitalismo, 2006; The fall of public man, 1976. 
servicios disponibles para el consumo le dieron al sujeto narcisista libertad para construir (o reconstruir) su identidad conforme a los sueños o aspiraciones transmitidas desde el mundo exterior, sobre todo las industrias culturales. Rotos los mismos diques que dejaron entrar el espacio público dentro del privado, más adelante fue el ámbito privado el que se "publificó" en base precisamente al espejo provisto por esas industrias culturales que, gracias a las tecnologías de comunicación interactiva, le permiten al sujeto ingresar "al otro lado" de ese espejo.

\section{La fragmentación del yo interior}

Recapitulemos diferenciando dos aspectos distintos en este proceso. Primero, la tendencia a revertir el tradicional ocultamiento de la intimidad, exponiéndolo a la luz pública. Y segundo, el predominio actual de la dimensión personal y emotiva en desmedro de lo racional y lo impersonal en los asuntos y personajes públicos.

Con respecto a lo primero, constatemos que el cine y la televisión inundaron el mundo de imágenes, de Puno a Samarcanda, de Hollywood a Kioto. Instauraron un régimen de visibilidad que da una fruición más vívida (pero acaso menos profunda) que la lectura de novelas o poemas. Todos estos relatos permitieron al lector o espectador identificarse y proyectarse en las ficciones presentadas, viviendo ella o él mismo, a través de interpósitos personajes, aquellas vivencias cuyo acceso la realidad les vedaba. De permanecer esos afanes admirativos o enamorados bien resguardados en la intimidad o en la confidencia, estos pasaron a ser progresivamente emulados, a medida que los modelos de vida fueron industrializándose y gradualmente pasando a ser consumibles a partir de fines del siglo XIX hasta la actualidad, inicialmente por minorías afortunadas, más adelante por audiencias masivas.

Subyace a este afán el pensar la propia vida como un relato que sigue un curso escogido por el sujeto. El sujeto moderno dispone de un resquicio de libertad en su fuero interior para descubrir que puede elaborar su propia imagen y decidir su destino. Sabiendo que ese narcisismo era explotable, el márketing y la publicidad echaron mano a la lógica mimética de los estilos de vida para aplicarla a otros campos masivos de consumo, con lo cual el espacio público cambió. Los afanes de mostrarse a sí mismo ante los otros para obtener de ellos nota aprobatoria devinieron en una aspiración socialmente legitimada. Esto contiene una clave para comprender la cultura del capitalismo tardío, pues se extiende por vastas zonas de lo simbólico: de la moda vestimentaria a la gastronomía, del diseño y decoración de interiores al negocio inmobiliario, pasando por cierto por las preferencias de entretenimiento, llegando al trabajo sobre el 
propio cuerpo (cirugía plástica y liposucción, así como gimnasios y dietas, entre otros), lo cual equivale a una puesta en escena pública de quien quiere uno "verdaderamente" ser.

En consonancia con este espíritu de época, se estaría pasando de la intimidad a cierta "extimidad", al propósito de "contarse" a sí misma(o) como en los antiguos diarios, pero ahora ante los otros, exhibiéndose directamente como los divos. Uno se pregunta si esas confidencias colgadas en el espacio virtual de la red son "obras" en la acepción literaria de la palabra, o en realidad acciones, experiencias de diálogo en línea con los otros. Habrá que conjeturar con Paula Sibilia que "[...] la experiencia vital de cada sujeto es una narración que solo puede pensarse y estructurarse como tal cuando el lenguaje la diseca y la modela". ${ }^{38}$ Los blogs puestos en línea exhiben opiniones y sentimientos que necesitan ser dichos sin inhibición, ya sea para atraer la atención o para ser discutidos y comentados, con lo cual el texto mismo va construyéndose, mostrando que todo discurso es dialógico y polifónico. ${ }^{39}$ Sitios de mostración de la identidad (o lo que de ella se consigne) de crecimiento rapidísimo, para libre intercambio y encuentro, del tipo MySpace, Hi5 o Face Book, entre otros, son una demos- tración palmaria de esta desenfadada exposición del sí mismo, sobre todo en los jóvenes "nativos digitales". Debe notarse que incluso si la identidad relatada o expuesta fuese simulada, estas prácticas estarían constituyendo de por sí un nuevo tipo de vínculo, en la medida en que un yo social fragmentado vive su propia invención con otro(s) acaso formados de manera semejante.

Esta intimidad expuesta en línea se apareja con otras formas de visibilización aparecidas antes de Internet, características también de la transformación de la subjetividad. Si hace dos siglos los deseos íntimos eran guardados en secreto o expuestos solo en el confesionario, en los años cincuenta se popularizaron los "correos del corazón", en los que anónimamente se pedía consejo en materia de desventuras amorosas. Actualmente las consultas radiales son de índole sexual explícita y cuentan con muchos testigos oyentes, como ocurre en el programa de la psicoterapeuta Lupe Maestre, transmitido diariamente a una audiencia multitudinaria por la red peruana RPP. Por cierto, el reality show y el talk o gossip show televisado para audiencias populares ha cundido. Trátese ya sea de espectáculos del tipo de Laura en América conducido por la discutida Laura Bozzo, expan-

38 SIBILIA, Paula. Op. cit., p. 39.

39 Ibídem, p. 38. 
dido a escala continental por la cadena Telemundo, con "panelistas" hechizos de guión aprendido, o de los veraces producidos en Europa con la participación de psicólogos ${ }^{40}$ sus éxitos de sintonía tienen mucho que ver con este deseo de ver la publificación de lo privado que se apareja con el de contarse a sí misma(o) ante los otros. Existe, por lo tanto, una avidez contemporánea por conocer lo real, lo verdaderamente acontecido, como si los géneros de ficción sufriesen un desgaste. Obviamente, el show de chismes de la periodista Magaly Medina, el programa de mayor sintonía en la televisión peruana, es la ilustración viva de esta tendencia.

Lo cual nos lleva al segundo aspecto de la publificación de la intimidad. Las cámaras del programa televisivo de Medina rebuscan los pequeños detalles transgresivos de la vida afectiva o sexual de personajes reconocidos por la audiencia, en general pertenecientes al mundo del espectáculo (esto le valió una pena de prisión en el 2008). Pero las ocurrencias grabadas generalmente tienen poco o nada que ver con la actuación pública de los personajes. Para los espectadores contaría entonces menos ese desempeño que aquello ocurrido detrás de las bambalinas. Lo escondido y revelado, o al revés puesto a la luz de buen grado, darían garantías de veracidad, suscitarían mejores emociones e identificaciones. Tomando un ejemplo, y sin hacer historiografía política ni menos tomar partido, recordemos la oratoria de Haya de la Torre en los grandes actos públicos apristas hasta la séptima década del siglo pasado. El atractivo de esos discursos radicaba en la emoción con que las ideas eran expresadas, en la pasión de la gente por aquello que sinceramente creía que le incumbía y por lo cual sería capaz de luchar. No había lugar para lo privado ahí. También contaba ese estar juntos de la manifestación cívica multitudinaria, en que se enardecían los ánimos. Hagamos una elipsis de varias décadas y pasemos a la Teletón promovida, a fines del 2008, por el presidente García con fines benéficos. Este programa televisado de larga duración le permitió ser visto por una audiencia de un volumen normalmente difícil de congregar, lucirse bailando con Gisela Valcárcel y otras damas de la farándula, y sobre todo mostrar una faceta afable y generosa, ideal para elevar su puntaje de aprobación en las encuestas. La figura del político carismático tradicional (que el mismo García adoptó en 1985) parece degradada, pasada de moda por su seriedad, frente al desfile de personajes fashion con el cual el presidente se intertextualiza, mientras su actuación fuera de su rol habitual nos lo presen-

40 MEHL, Dominique. La télévision de l'intimité, 1997. 
ta como "verdaderamente" es. (Añadamos que mientras la finalidad de las grandes manifestaciones colectivas premediáticas fue de ver y oír a una figura de la que solo se tenía referencias lejanas, ahora los vemos hasta en la sopa, es decir por televisión o en YouTube.)

Este prurito de hacer "real" la bondad del hombre público haciéndolo emocionalmente más cercano lleva a la simulación de enunciadores y de roles con que funciona la comunicación política actual. Esto probablemente se acrecentará a medida que cada aspirante a hombre público se haga presente en el ciberespacio con página propia y su mejor rostro, hecha por otros o por él. En cambio, podrá haber muchos otros enunciadores en línea con otros tipos de contenido que, al contrario, tienen la posibilidad de afirmar lo que el espacio público "personalizado" de la publicidad y el márketing no da espacio para decir porque no vende bien, incomoda al poder o se dirige solo a un yo tan diferenciado que, aun ocupándose de asuntos capitales, solo tiene unos pocos interlocutores.

En suma, esas limitaciones al debate, más la intimidad exhibida en el centro del ámbito público y el yo fragmentado o simulado son algunos de los síntomas del malestar de una época de "descomposición de lo social", que anuncia el surgimiento de un individualismo triunfal como nuevo principio moral. ${ }^{41} \mathrm{El}$ rumbo de internet (originado con el proyecto Arpanet del Departamento de Defensa de Estados Unidos) cambió gracias a una conjunción de factores, y sus aplicaciones civiles posteriores resultaron benéficas con creces, aunque hayan traído una serie de consecuencias que por el momento son solo materia de juicios de valor. La lectura de libros, sobre todo los de contenidos densos, disminuye, prestigiosos diarios tienen problemas de ventas. La novela, alguien lo ha previsto, quizá desaparezca en unas décadas, y el cine de largometraje junto con la escucha musical tomarían el rumbo del easy listening y el easy viewing. ${ }^{42}$ La transformación de la subjetividad que esto conlleva es, por lo tanto, un "accidente" no previsto -en el sentido de Virilio- debido a las distorsiones y desigualdades que esto entraña. Sin embargo, los procesos de adaptación podrán traer, al contrario, una explosión de la creatividad y lazos sociales más auténticos y libres. Pensarlo, comprenderlo y ser optimista es parte del compromiso ético del trabajo intelectual de nuestro tiempo.

41 TOURAINE, Alain. Un nouveau paradigme. Pour comprendre le monde d'aujourd'hui, 2005, pp. 30-31.

42 SIBILIA, Paula. Op. cit., pp. 43 y 56. 


\section{Bibliografía}

BAUMAN, Zygmunt. Vida de consumo. Buenos Aires: Fondo de Cultura Económica, 2007.

CASETTI, F. y R. ODIN. De la paléo- à la néo-télévision. Communications 51, Télévisions/ mutations. París: EHESS/ Centre d'Études Transdisciplinaires /Éditions du Seuil, 1990.

CHARTIER, Roger. El juego de las reglas. Lecturas. México: Fondo de Cultura Económica, 2000.

ECO, Umberto. La estrategia de la ilusión. Barcelona: Lumen, 1986.

FERRY, Jean-Marc. "Las transformaciones de la publicidad política", en VARIOS AUTORES. El nuevo espacio público. Barcelona: Gedisa, 1998.

FOUCAULT, Michel. Historie de la sexualité. 1 . La volonté de savoir. París: Gallimard, 1976.

GIDDENS, Anthony. The transformation of intimacy. Sexuality, love, and eroticism in modern societies. Stanford: Stanford University Press, 1992.

HERLINGHAUS, Hermann. “La imaginación melodramática. Rasgos intermediales y heterogéneos de una categoría precaria", en HERLINGHAUS, H. (ed.). Narraciones anacrónicas de la modernidad: $M e-$ lodrama e intermedialidad en América Latina. Santiago de Chile: Editorial Cuarto Propio, 2002.
LASCH, Christopher. The culture of narcissism. American life in an age of diminishing expectations. Nueva York: Warner Books, 1979.

LOHMANN VILLENA, Guillermo y Juan GÜNTHER DOERING. Lima. Madrid: Mapfre, 1992.

LÓPEZ JIMÉNEZ, Sinesio. Ciudadanos reales e imaginarios. Concepciones, desarrollo y mapas de la ciudadanía en el Perú. Lima: Instituto de Diálogo y Propuestas, 1998.

MEHL, Dominique. La télévision de l'intimité. París: Éditions du Seuil, 1995.

MIÈGE, Bernard. "L'espace public: audelà de la sphère politique. Hermès 17-18. París: CNRS éditions, 1995.

MONSIVÁIS, Carlos. Aires de familia. Cultura y sociedad en América Latina. Barcelona: Anagrama, 2000.

PORTOCARRERO, Gonzalo. "La transgresión como forma específica de goce del mundo criollo", en LÓPEZ MAGUIÑA, S. et al. Estudios culturales. Discursos, poderes, pulsiones. Lima: PUCP/CIUP/IEP/ Red para el Desarrollo de las Ciencias Sociales en el Perú, 2001.

_- "Las nuevas poéticas del sujeto en la sociedad peruana", en LOHMANN VILLENA, G. Historia de la cultura peruana, tomo 2. Lima: Congreso de la República, 2001.

SENNETT, Richard. La cultura del nuevo capitalismo. Barcelona: Anagrama, 2006. 
- The fall of public man. Nueva York-Londres: W. W. Norton \& Company, 1976.

SIBILIA, Paula. La intimidad como espectáculo. Buenos Aires: Fondo de Cultura Económica, 2008.

TOURAINE, Alain. Un nouveau paradigme. Pour comprendre le monde d'aujourd'hui. París: Fayard, 2005.
VELÁSQUEZ, Marcel. "Novela romántica y nación: Memorias f(r)iccionales y subjetividades protésicas", en HAMANN, M. et al. Batallas por la memoria: Antagonismos de la promesa peruana. Lima: PUCP/ CIUP/IEP/ Red para el Desarrollo de las Ciencias Sociales en el Perú, 2003.

VIRILIO, Paul. L'accident originel. París: Galilée, 2005. 